\title{
Breast cancer risk factors in south of Islamic Republic of Iran: a case- control study
}

K. Mahouri, ${ }^{1}$ M. Dehghani Zahedani ${ }^{2}$ and S. Zare ${ }^{2}$

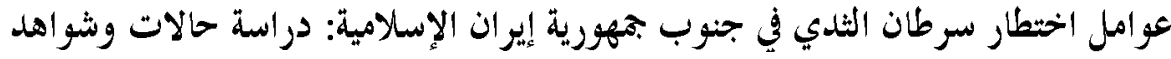

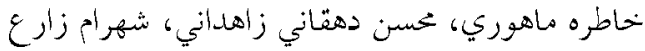

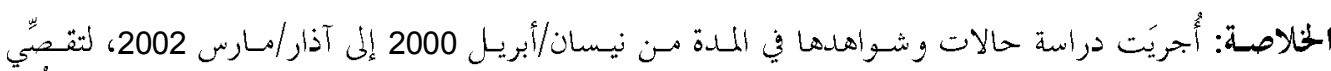

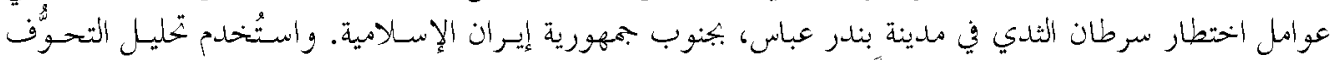

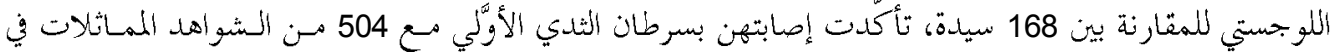

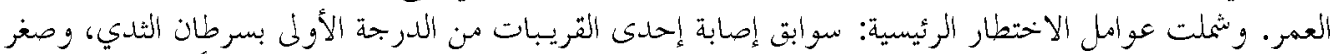

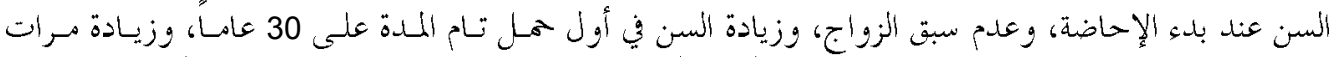

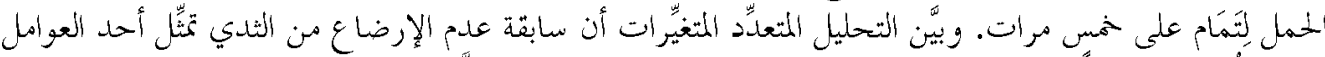

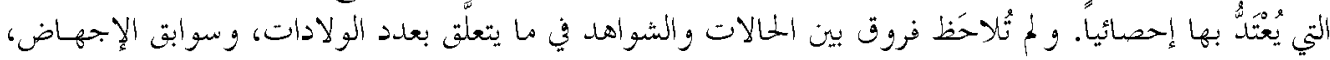

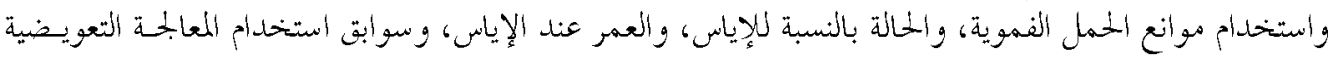

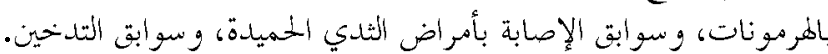

ABSTRACT A case-control study was carried out from April 2000 to March 2002 to investigate risk factors for breast cancer in Bandar Abbas, south Islamic Republic of Iran. Using logistic regression analysis, 168 women with pathologically confirmed primary breast cancer were compared with 504 age-matched controls. Significant risk factors were: family history of breast cancer in a first-degree relative, younger age at menarche, never married, first full-term pregnancy age $30+$ years and $>5$ fullterm pregnancies. In multivariate analysis, negative history of breastfeeding was also significant. Cases and controls did not differ with regard to parity, history of abortion, oral contraceptive use, menopausal status, age at menopause, ever-use of hormone replacement therapy, history of benign breast disease or history of cigarette smoking.

Les facteurs de risque de cancer du sein dans le sud de la République islamique d'Iran : une étude cas-témoins

RÉSUMÉ Une étude cas-témoins a été menée entre avril 2000 et mars 2002 à Bandar Abbas, dans le sud de la République islamique d'Iran, afin d'évaluer les facteurs de risque de cancer du sein. Cette étude a comparé, sur la base de la régression logistique, 168 patientes présentant un cancer du sein primitif confirmé par l'anatomopathologie avec 504 femmes témoins appariées en âge. L'analyse a identifié les facteurs de risque significatifs suivants : histoire familiale de cancer du sein au premier degré de parenté, apparition plus précoce des premières règles, absence de mariage, primiparité à terme au-delà de 30 ans et plus de 5 grossesses menées à terme. L'analyse multivariée a également montré l'importance d'une histoire négative d'allaitement au sein. Les cas et les témoins se sont avérés comparables en termes de parité, d'histoire d'avortement, d'utilisation de contraceptifs oraux, de statut ménopausique, d'âge à la ménopause, de naïveté de tout traitement hormonal substitutif, d'antécédents de pathologie mammaire bénigne et de tabagisme.

${ }^{1}$ Department of Community Medicine; ${ }^{2}$ Department of Pathology, Bandar Abbas School of Medicine, Bandar Abbas, Islamic Republic of Iran (Correspondence to K. Mahouri: khmahoori@yahoo.com).

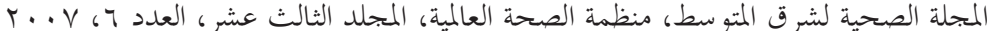




\section{Introduction}

Similar to other human cancers, breast cancer arises from a multifactorial process. Recent attention has focused on genetic predisposition to breast cancer $[1,2]$ and on its association with factors relating to modern affluence, including diet and alcohol consumption [3-5]. Furthermore, the effect of reproductive factors strongly supports a hormonal role in its etiology in some industrialized countries [6,7]. Earlier age at menarche $[8-10]$ and later age at first full-term pregnancy [9-12] are associated with a significant increase in the risk of the disease, whereas the few studies that have been conducted in northern and central parts of the Islamic Republic of Iran have not confirmed a significant effect of these factors [13-15].

While numerous studies have been conducted in industrialized countries to assess the epidemiology of breast cancer, there have been few studies in Eastern Mediterranean Region populations. Such studies are of interest because their different risk profiles may help to explain the different occurrence of the disease in different populations. Although breast cancer is the most common form of cancer in Iranian women [16], few epidemiological studies have been conducted on its risk factors, especially in the south of the country. The age-adjusted incidence of the disease is estimated to be 22.4 per 100000 [16]. Epidemiological studies have revealed a lower age of Iranian patients compared with their counterparts in industrialized countries $[14,17]$ and a moderately rapid increase in the incidence of the disease in recent years [16]. The question therefore arises as to whether or not breast cancer in the south of the Islamic Republic of Iran is influenced by some of the risk factors previously established in studies of high or moderate incidence areas.
This case-control study was undertaken to investigate this subject and the inconsistency between the results of the studies in northern and central parts of the Islamic Republic of Iran and populations elsewhere.

\section{Methods}

A case-control study was conducted from April 2000 to March 2002 in Bandar Abbas city, Hormozgan, Islamic Republic of Iran. Hormozgan province is the southernmost province of the country located along the Straits of Hormoz.

The eligible cases were all incident (i.e. diagnosed within 2 years before the interview) breast cancer patients living in the city during the study period. We approached 173 women with primary breast cancer who were eligible for our study but only 168 agreed to participate, giving a participation rate for cases of $97.1 \%$.

Women were entered into the study if they had a confirmed pathological primary breast cancer diagnosis from the pathology department of Bandar Abbas Shahid Mohammadi Hospital, the leading universitybased hospital in the region. For each case, 3 age-matched (to within 3 years) women were recruited from patients without any history of breast problems or neoplastic diseases who attended the outpatient ophthalmology or dermatology clinic in the same hospital. Women with a history of hysterectomy or artificial menopause were excluded from the study.

After taking informed consent from the women, a structured questionnaire was administered was completed at the time of recruitment including the following: demographic characteristics, family history of breast cancer in a first-degree relative, age at menarche, marital status, parity, age at first full-term pregnancy, number of chil- 
dren or full pregnancies, history of previous breastfeeding (defined as having breastfed for $>2$ months), history of induced or spontaneous abortion, history of ever-use of oral contraceptives, menopausal status, age at menopause, history of ever-use of hormone replacement therapy (HRT), past history of benign breast disease and history of cigarette smoking. All interviews were carried out by 2 interviewers who had been thoroughly familiarized with the study protocol.

This study did not use 'blinding' procedures with respect to the case status of subjects and it is possible that women who were diagnosed with breast cancer were more likely to provide more detailed complete information about past exposure history than controls. However, the investigators and the interviewers were fully informed about the possibility of recall/interviewer bias and their potential impact on our study. A number of efforts were made to minimize such bias, including standardization of wording in the interview and repeat interviews for some participants.

Odds ratios from univariate logistic regression were used to estimate the relative risk of breast cancer associated with the various factors, and their predictive effects. Based on the univariate analysis, the odds ratios (OR) were adjusted for potential confounding variables and $95 \%$ confidence intervals (CI) were calculated. A forward multivariate logistic regression model was used for significant associated risk factors and $P<0.05$ was considered statistically significant.

\section{Results}

Of 173 women with breast cancer who were newly diagnosed, 168 patients were entered in the study as cases and 504 women were selected as controls. As controls were age-matched with cases, there was no significant difference between the mean age of the 2 groups: 48.6 [standard deviation (SD) 13.7] years for cases versus 48.4 (SD 13.6) years for controls (Table 1).

The results of univariate binary logistic regression analysis are shown in Table 2. There were no significant differences between cases and controls with regard to parity, history of breastfeeding, history of induced or spontaneous abortion, oral contraceptive use, menopausal status, age at menopause, history of HRT use, history of previous benign breast disease or having ever smoked cigarettes.

However, breast cancer history in a firstdegree relative was a significant risk factor (OR 9.07, 95\% CI: 4.06-12.26). Women with younger age at menarche $(<13$ years old) were found to be at higher risk for breast cancer than women with older age of menarche (OR 4.00, 95\% CI: 1.82-9.84). Never married women demonstrated a higher risk of breast cancer than the others (OR 2.69, 95\% CI: 1.38-7.12). Breast cancer risk was significantly greater in women where first full-term pregnancy was at age $30+$ years in comparison with the others with first full-term pregnancy at lower age

\begin{tabular}{|c|c|c|c|c|}
\hline \multirow[t]{2}{*}{ Age (years) } & \multicolumn{2}{|c|}{$\begin{array}{c}\text { Cases } \\
(n=168)\end{array}$} & \multicolumn{2}{|c|}{$\begin{array}{l}\text { Controls } \\
(n=504)\end{array}$} \\
\hline & No. & $\%$ & No. & $\%$ \\
\hline$<35$ & 24 & 14.2 & 67 & 13.3 \\
\hline $36-45$ & 54 & 32.1 & 162 & 32.1 \\
\hline $46-55$ & 33 & 19.6 & 124 & 24.7 \\
\hline$>55$ & 57 & 33.9 & 151 & 29.9 \\
\hline Mean (SD) & \multicolumn{2}{|c|}{$48.6(13.7)$} & \multicolumn{2}{|c|}{$48.4(13.6)$} \\
\hline Range & \multicolumn{2}{|c|}{ 27-92 } & \multicolumn{2}{|c|}{$25-95$} \\
\hline
\end{tabular}

$S D=$ standard deviation

$\mathrm{n}=$ total number of respondents.

المجلة الصحية لشرق المتوسط، منظمة الصحة العالمية، المجلد الثالث عشر، العدد Y، V... 
Table 2 Distribution of breast cancer cases and controls according to selected risk factors and associated odds ratios derived from univariate logistic regression analysis

\begin{tabular}{|c|c|c|c|c|c|c|}
\hline \multirow[t]{2}{*}{ Parameter } & \multicolumn{2}{|c|}{ Cases $(n=168)$} & \multicolumn{2}{|c|}{ Controls $(n=504)$} & \multirow[t]{2}{*}{ OR $(95 \% \mathrm{CI})$} & \multirow[t]{2}{*}{$P$-value } \\
\hline & No. & $\%$ & No. & $\%$ & & \\
\hline \multicolumn{7}{|c|}{ Family history of breast cancer } \\
\hline No & 154 & 91.7 & 499 & 99.1 & $1.00^{\mathrm{a}}$ & \\
\hline Yes & 14 & 8.3 & 5 & 0.9 & $9.07(4.06-12.26)$ & $P<0.01$ \\
\hline \multicolumn{7}{|l|}{ Age at menarche (years) } \\
\hline$<13$ & 49 & 29.2 & 47 & 9.3 & $4.00(1.82-9.84)$ & $P<0.01$ \\
\hline$\geq 13$ & 119 & 70.8 & 457 & 90.7 & $1.00^{\mathrm{a}}$ & \\
\hline \multicolumn{7}{|l|}{ Marital status } \\
\hline Married & 128 & 76.2 & 425 & 84.3 & $1.00^{\mathrm{a}}$ & \\
\hline Divorced/widowed & 28 & 16.7 & 65 & 12.9 & $1.43(0.88-3.76)$ & \\
\hline Never married & 12 & 7.1 & 14 & 2.8 & $2.69(1.38-7.12)$ & $P<0.05$ \\
\hline \multicolumn{7}{|l|}{ Parity } \\
\hline Parous & 154 & 91.7 & 490 & 97.2 & $1.00^{\mathrm{a}}$ & \\
\hline Nulliparous & 14 & 8.3 & 14 & 2.8 & $3.18(0.77-12.26)$ & NS \\
\hline \multicolumn{7}{|c|}{$\begin{array}{l}\text { Age at first full-term pregnancy } \\
\text { (years) }\end{array}$} \\
\hline$\leq 30$ & 144 & 85.7 & 481 & 95.4 & $1.00^{\mathrm{a}}$ & \\
\hline$>30$ & 7 & 4.2 & 3 & 0.6 & $7.79 \quad(4.25-9.12)$ & $P<0.01$ \\
\hline (Nulligravida) & 17 & 10.1 & 20 & 4.0 & & \\
\hline \multicolumn{7}{|c|}{ No. of full-term pregnancies } \\
\hline 0 & 17 & 10.1 & 20 & 4 & & \\
\hline $1-2$ & 26 & 15.5 & 98 & 19.4 & & \\
\hline $3-5$ & 57 & 33.9 & 278 & 55.2 & & \\
\hline$>5$ & 68 & 40.5 & 108 & 21.4 & & \\
\hline \multicolumn{7}{|l|}{ History of breastfeeding } \\
\hline No & 13 & 7.7 & 27 & 5.4 & $1.00^{\mathrm{a}}$ & \\
\hline Yes & 155 & 92.3 & 477 & 94.6 & $0.68 \quad(0.12-0.97)$ & NS \\
\hline \multicolumn{7}{|l|}{$\begin{array}{l}\text { History of induced or } \\
\text { spontaneous abortion }\end{array}$} \\
\hline No & 128 & 76.1 & 387 & 76.8 & $1.00^{\mathrm{a}}$ & \\
\hline Yes & 44 & 23.9 & 117 & 23.2 & $1.14 \quad(0.48-2.26)$ & NS \\
\hline \multicolumn{7}{|c|}{ History of oral contraceptive } \\
\hline \multicolumn{7}{|l|}{ use } \\
\hline No & 137 & 81.5 & 403 & 79.9 & $1.00^{\mathrm{a}}$ & \\
\hline Yes & 31 & 18.5 & 101 & 20.1 & $0.91 \quad(0.39-1.99)$ & NS \\
\hline \multicolumn{7}{|l|}{ Menopausal status } \\
\hline Premenopause & 81 & 48.2 & 236 & 46.8 & $1.00^{\mathrm{a}}$ & \\
\hline Postmenopause & 87 & 51.8 & 268 & 53.2 & $0.95 \quad(0.43-2.28)$ & NS \\
\hline \multicolumn{7}{|c|}{ Age at menopause (years) } \\
\hline$<45$ & 8 & 4.8 & 29 & 5.7 & & \\
\hline $45-50$ & 57 & 33.9 & 207 & 41.1 & & \\
\hline$>50$ & 22 & 13.1 & 32 & 6.4 & & \\
\hline
\end{tabular}


Table 2 Distribution of breast cancer cases and controls according to selected risk factors and associated odds ratios derived from univariate logistic regression analysis (concluded)

\begin{tabular}{|c|c|c|c|c|c|c|}
\hline \multirow[t]{2}{*}{ Parameter } & \multicolumn{2}{|c|}{ Cases $(n=168)$} & \multicolumn{2}{|c|}{ Controls $(n=504)$} & \multirow[t]{2}{*}{ OR $(95 \% \mathrm{Cl})$} & \multirow[t]{2}{*}{$P$-value } \\
\hline & No. & $\%$ & No. & $\%$ & & \\
\hline \multicolumn{7}{|c|}{ History of HRT use } \\
\hline No & 77 & 42.3 & 239 & 41.5 & $1.00^{\mathrm{a}}$ & \\
\hline Yes & 10 & 6.0 & 29 & 5.4 & $1.09(0.53-1.82)$ & NS \\
\hline \multicolumn{7}{|c|}{$\begin{array}{l}\text { History of previous benign } \\
\text { breast diseases }\end{array}$} \\
\hline No & 161 & 95.8 & 492 & 97.7 & $1.00^{\mathrm{a}}$ & \\
\hline Yes & 7 & 4.2 & 12 & 2.4 & $1.78(0.83-3.12)$ & NS \\
\hline \multicolumn{7}{|c|}{ History of cigarette smoking } \\
\hline No & 101 & 60.1 & 315 & 62.5 & $1.00^{\mathrm{a}}$ & \\
\hline Yes & 67 & 39.9 & 189 & 37.5 & $1.13(0.58-2.16)$ & NS \\
\hline
\end{tabular}

${ }^{a}$ Reference category.

$N S=$ not significant, $\mathrm{Cl}=$ confidence interval; $\mathrm{OR}=$ odds ratio; $H R T=$ hormone replacement therapy. $\mathrm{n}=$ total number of respondents.

(OR 7.79, 95\% CI: 4.25-9.12) (Table 2 ). Furthermore, it was shown that $>5$ full-term pregnancies would be expected to correlate with an increase in the risk of breast cancer $\left(\chi^{2}=111.12, P<0.05\right)$.

In forward multivariate logistic regression analysis, in addition to those factors which were significantly associated with breast cancer, parity and breastfeeding were included in the model because of their relatively high but not statistically significant OR. The final model revealed that in addition to those factors which were significant in univariate logistic regression analysis, negative history of breastfeeding was a significant factor in increasing risk of breast cancer (OR 1.55, 95\% CI: 1.08-2.90), but nulliparity remained not significant.

\section{Discussion}

The purpose of the present study was to characterize breast cancer epidemiology, especially in determining the generally accepted or suspected risk factors in the Islamic Republic of Iran.

As in industrialized countries, we found that a family history of breast cancer was an important factor contributing to breast cancer in the south of the Islamic Republic of Iran. This observed familial association is likely to imply a genetic predisposition. Therefore, it is of interest to determine whether known breast cancer susceptibility genes, such as BRCA1 [18] and BRCA2 [19], responsible for a proportion of breast cancers in other countries [8,9,20], also play a role in breast cancer in Islamic Republic of Iran.

The relation between women's risk of breast cancer and reproductive history has been the subject of many investigations [5-17,21-31]. Despite the large number of studies, the findings for reproductive risk factors have been inconsistent. Our findings suggest an inverse relationship between age at menarche and breast cancer risk, which is consistent with findings in some studies

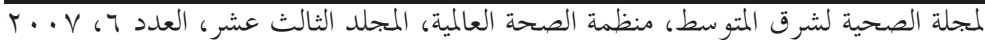


[8-10], although it was not a significant risk factor for breast cancer in some other populations $[5,11,13-15,17]$. The basis of this difference in different populations is not clear and warrants further study.

The findings of our study show that never married women were at higher risk for breast cancer. However, results of multivariate logistic regression analysis revealed that nulliparity was not a statistical significant risk factor for breast cancer. These results are in agreement with the results of another study on the Iranian population [17]. In some studies, single and nulliparous married women were found to have a similar increased risk for breast cancer as compared with parous women of the same age [21]. Thus one possible explanation for these results is that marital status or nulliparity by itself is not a determining factor for increased or decreased beast cancer risk, and rather the main effect is due to age at first full-term pregnancy or parity number.

Our findings clearly suggest that older age at first full-term pregnancy increased the risk of breast cancer. Although this result is consistent with some studies in different nations and ethnic groups [9-12], it is inconsistent with findings from some other studies and particularly from studies in northern and central parts of the Islamic Republic of Iran [5, 8, 13-15,17].

Although on the basis of a suggested influence of full-term pregnancy on breast cells [22] an increase in full-term pregnancies would be expected to correlate with a decreased risk of breast cancer in some women $[8,11,23]$, evidence suggest that there is a dual effect of parity on breast cancer risk with pregnancy $[11,24,25]$. Our findings showed that more than 5 fullterm pregnancies would be expected to correlate with an increase in the risk of breast cancer.
The results of the few studies in northern and central parts of Islamic Republic of Iran do not indicate a significant relationship between history of breastfeeding and breast cancer rate [13-15], but according to the results of the present study, the protective effect of breastfeeding was clear on multivariate analysis. This finding is consistent with a large collaborative study [26] and some other studies in different populations $[5,8,9,11,23,27-29]$ showing breastfeeding to be protective for breast cancer through hormonal or other mechanisms.

Recent reviews reach conflicting conclusions on breast cancer risk after spontaneous or induced abortion [13,15,30,31]. In our study, history of abortion, either spontaneous or induced, was not found to be correlated to breast cancer.

Disagreement remains in the literature on the direction and magnitude of effect, if any, of oral contraceptive use on breast cancer risk [5,8,9,17,28,32-34]. Despite large studies designed to address such differences, chance, selection factors, changes in formulations, pattern of use and different background risk for breast cancer might account for some of the variation in findings. No association was found between the use of oral contraceptives and breast cancer risk in our study participants.

Our results show that there was no large difference in ever-use of HRT among cases and controls, which was similar to some recent case-control studies [5,35]. However, a small increased risk has been observed in larger studies [36,37], which might be accounted for by the specific questions about types of HRT and the small sample size of our study; future studies may need to examine the detail of different HRT regimens and duration or age of use.

Smoking history was not associated with breast cancer risk. This result is in 
agreement with the results of some other studies $[5,8]$.

A number of limitations such as the small sample size and the selection of case and controls may affect the interpretation of our results. Although the results cannot be generalized, the findings suggest that the associations between some known risk factors for breast cancer may differ in the south of the Islamic Republic of Iran as compared with other populations. Intensive studies of breast cancer risk factors in developing countries might reveal other important risk factors in these populations.

\section{Acknowledgements}

We thank Sepideh Ebrahimi and Maria Rezazadeh for interviewing and study assistance. We are also grateful for the time and commitment of the study participants.

\section{References}

1. Sattin RW et al. Family history and the risk of breast cancer. Journal of the American Medical Association, 1985, 253:1908-13.

2. Fisher B et al. Neoplasms of the breast. In: Holland JF et al., eds. Cancer medicine, 3rd ed. Philadelphia, Lea \& Febiger, 1993:1706-74.

3. Hunter DJ, Willett WC. Diet, body size and breast cancer. Epidemiologic reviews, 1993, 15:256-63.

4. Rosenberg L, Metzger LS, Palmer JR. Alcohol consumption and risk of breast cancer: a review of the epidemiologic evidence. Epidemiologic reviews, 1993 15:133-44.

5. Wrensch $\mathrm{M}$ et al. Risk factors for breast cancer in a population with high incidence rates. Breast cancer research, 2003, 5(4): R88-R102.

6. Kelsey JL, Gammon MD, John EM. Reproductive factors and breast cancer. Epidemiologic reviews, 1993, 15:36-47.

7. Pike MC et al. Estrogens, progestogens, normal breast cell proliferation, and breast cancer risk. Epidemiologic reviews, 1993 , 15(1):17-35.

8. Yang PS et al. A case-control study of breast cancer in Taiwan: a low incidence area. British journal of cancer, 1997 , 75(5):752-6.
9. Kuru B et al. Risk factors for breast cancer in Turkish women with early pregnancies and long lasting lactation: a case-control study. Acta oncologica, 2002, 41(6):55661.

10. Tavani A et al. Risk factors for breast cancer in women under 40 years. European journal of cancer, 1999, 35(9):1361- 7.

11. Gilliland FD et al. Reproductive risk factors for breast cancer in Hispanic and nonHispanic white women. American journal of epidemiology, 1998, 148(7):683-92.

12. Oran B et al. Analysis of menstrual, reproductive, and life-style factors for breast cancer risk in Turkish women: a casecontrol study. Medical oncology, 2004, 21(1):31-40

13. Kashfi F, Nikoofar AR, Mohammadi R. Fertility risk factors causing breast cancer. Medical journal of reproduction \& infertility, 2002, 3(1):45-8.

14. Motamed N, Hadi N, Talei AR. A survey on risk factors of beast cancer in women over 35 years of age, Shiraz, 2000. Journal of Zanjan University of Medical Sciences and Health Services, 2004, 46(12):25-32.

15. Pessaran $Z$ et al. Evaluation of breast cancer risk factors for using in hormone replacement therapy of corticosteroid-treated

المجلة الصحية لشرق المتو سط، منظمة الصحة العالمية، المجلد الثالث عشر، العدد Y، V... 
post-menopausal women. Shahrekord University of Medical Sciences journal, 2003, 2(5):70-5.

16. Mohagheghi MA. Epidemiology of breast cancer in Iran. In: Mirbod P, ed. Proceedings of the 14th Annual Meeting of Cancer Institute: 23-25 October 2002, Tehran, Iran. Tehran, Tehran University of Medical Sciences, 2002:2-10.

17. Ebrahimi M, Vahdaninia M, Montazeri A. Risk factors for breast cancer in Iran: a case-control study. Breast cancer research, 2002, 4(5):R10.

18. Miki $Y$ et al. A strong candidate for the breast and ovarian cancer susceptibility gene BRCA1. Science, 1994, 266:66-71.

19. Wooster $R$ et al. Identification of the breast cancer susceptibility gene BRCA2. Nature, 1995, 378:789-92.

20. Negri $E$ et al. Family history of cancer and risk of breast cancer. International journal of cancer, 1997, 72:735-8.

21. Rosner B, Colditz GA, Willett WC. Reproductive risk factors in a prospective study of breast cancer: the nurses' health study. American journal of epidemiology, 1994, 139:819-35.

22. Russo J, Tay LK, Russo IH. Differentiation of the mammary gland and susceptibility to carcinogenesis. Breast cancer research and treatment, 1982, 2:5-73.

23. Minami $Y$ et al. Risk factors for breast cancer: a case-control study of screendetected breast cancer in Miyagi Prefecture, Japan. Breast cancer research and treatment, 1997, 44(3):225-33.

24. Hsieh C et al. Dual effect of parity on breast cancer risk. European journal of cancer, 1994, 30A:969-73.

25. Palmer $J \mathrm{R}$ et al. Dual effect of parity on breast cancer risk in African-American women. Journal of the National Cancer Institute, 2003, 95(6):478-83.
26. Collaborative Group on Hormonal Factors in Breast Cancer. Breast cancer and breastfeeding: collaborative reanalysis of individual data from 47 epidemiological studies in 30 countries, including 50302 women with breast cancer and 96973 women without the disease. Lancet, 2002, 360:187-95.

27. Freudenheim $\mathrm{JL}$ et al. Lactation history and breast cancer risk. American journal of epidemiology, 1997, 147(11):932-8.

28. Zhao Y, Shi Z, Liu L. Matched casecontrol study for detection of breast cancer in women living in Chengdu. Chinese journal of epidemiology, 1999, 20(2):91-4.

29. Alavi Naini M, Gholami K. The relation between breast feeding and breast cancer. Iranian journal of public health, 1998, 1-2(27):61-70.

30. Paoletti X, Clavel-Chapelon F. Induced and spontaneous abortion and breast cancer risk: results from the $\mathrm{E} 3 \mathrm{~N}$ cohort study. International journal of cancer, 2003, 106(2):270-6.

31. Palmer JR et al. Induced and spontaneous abortion in relation to risk of breast cancer (United States). Cancer causes \& control, 1997, 8(6):841-9.

32. Kelsey JL, Bernstein L. Epidemiology and prevention of breast cancer. Annual review of public health, 1996, 17:47-67.

33. Marchbanks PA et al. Oral contraceptives and the risk of breast cancer. New England journal of medicine, 2002, 346:202532.

34. Collaborative Group on Hormonal Factors in Breast Cancer. Breast cancer and hormonal contraceptive: further results. Contraception, 1996, 54:1S-106S.

35. Davis S, Mirick DK, Stevens RG. Residential magnetic fields and the risk of breast cancer. American journal of epidemiology, 2002, 155:446-54. 
36. Collaborative Group on Hormonal Factors in Breast Cancer. Breast cancer and hormone replacement therapy: collaborative reanalysis of data from 51 epidemiological studies of 52705 women with breast cancer and 108411 women without breast cancer. Lancet, 1997, 350:1047-59.
37. Writing Group for the Women's Health Initiative Investigators. Risk and benefits of estrogen plus progestin in healthy postmenopausal women: principal results from the Women's Health Initiative randomized controlled trial. Journal of the American Medical Association, 2002, 288:321-33.

\section{Global age-friendly cities: a guide}

Population ageing and urbanization comprise major forces shaping the 21st century. At the same time as cities are growing, their share of residents aged 60 years and over is increasing. Older people are a resource for their families, communities and economies.

The World Health Organization (WHO) regards active ageing as a lifelong process shaped by several factors that favour health, participation and security in older adult life. The purpose of this Guide is to engage cities to become more age-friendly so as to tap the potential that older people represent for humanity.

WHO asked older people, caregivers and service providers living in 33 cities in all WHO regions to describe the advantages and barriers they experience in eight areas of city living. The results led to the development of a set of age-friendly city checklists.

The challenge facing cities and the "active ageing" concept are outlined. Issues and concerns voiced by older people and those who serve older people are highlighted. The principal traits of the "ideal" age-friendly city are listed and the Guide shows how changing one aspect of the city can have positive effects on the lives of older people in other areas.

WHO collaborators are now undertaking initiatives to translate the research into local action, to expand the scope beyond cities, and to spread it to more communities. An age-friendly community movement is growing, for which this Guide is the starting point. It can be downloaded from: http://www.who.int/ageing/publications/Global_ age_friendly_cities_Guide_English.pdf 